\title{
La movilidad de los mejores: Políticas migratorias para jóvenes y nuevos saberes de estado en el contexto español
}

\author{
The Mobility of the Best: Migration Policies and State Knowledge in the Spanish \\ Context
}

Débora Betrisey Nadali ${ }^{1}$

\section{RESUMEN}

Este artículo se centra en las políticas migratorias del estado español destinadas a fomentar la denominada movilidad de jóvenes españoles durante la última década. Desde una perspectiva socioantropológica, analizamos dichas políticas como parte de técnicas de gobierno encarnadas en un saber institucional y moral que ayuda a conformar nuevas categorías y subjetividades de emigrantes que conjugan figuras históricas (aventureros, conquistadores) y valores de las élites económicas globales (talento, capacidad de triunfo, etcétera). Además, sostenemos que, a través de estos dispositivos, se extrae un modelo para la acción que convierte la denominada movilidad de jóvenes en una fuerza emancipadora, al mismo tiempo que niega las condiciones de dominación sobre la que se sustenta. Con este trabajo procuramos contribuir a una mayor comprensión de las lógicas culturales y sociopolíticas en la que se insertan algunas de las actuales políticas migratorias en el contexto español.

Palabras clave: 1. emigración española, 2. políticas migratorias, 3. movilidad internacional, 4. neoliberalismo, 5. España.

\section{ABSTRACT}

This paper focuses on current migration policies of the Spanish State aimed at promoting the socalled international mobility of young Spanish citizens over the last decade. From a socioanthropological perspective, it analyses these policies as part of government techniques embodied in an institutional and moral knowledge that helps shape new categories and subjectivities of immigrants by combining historical figures (adventurers, conquerors) and values of global economic elites (talent, ability to succeed, etcetera). Moreover, it is argued that, through these devices, a model for action emerges that turns so-called youth mobility into an emancipation force while denying the conditions of domination on which it is sustained. This paper attempts to contribute a greater understanding of the cultural and socio-political logics that justifies the present migration policies in the Spanish context.

Keywords: 1. Spanish emigration, 2. migration policies, 3. international mobility, 4. neoliberalism, 5. Spain.

Fecha de recepción: 17 de diciembre de 2018

Fecha de aceptación: 29 de abril de 2020

Fecha de publicación web: 15 de noviembre de 2020

\footnotetext{
${ }^{1}$ Universidad Complutense de Madrid, España, dbetrisey@ cps.ucm.es, http://orcid.org/0000-0002$\underline{2706-8393}$
}

Migraciones Internacionales es una revista digital anual editada por El Colegio de la Frontera Norte. https://migracionesinternacionales.colef.mx 


\section{INTRODUCCIÓN ${ }^{2}$}

En los últimos años, estimular y planificar la llamada movilidad internacional de jóvenes españoles forma parte de las principales políticas migratorias del estado español. ${ }^{3}$ Dicha política se presenta como parte de un intercambio temporal de población menor de 35 años, con el fin de trabajar, estudiar o vacacionar en diversos países (Alemania, Canadá, Nueva Zelanda, Australia o Japón) como parte de un equilibrio perfecto (dar-tomar-recibir) entre los países que envían y acogen esta población y los propios protagonistas de tales movimientos. Cabe mencionar que las referencias a la movilidad no solo aparecen recogidas en las políticas migratorias, sino también en las diversas reformas laborales vinculadas a políticas neoliberales (Harvey, 2007), ${ }^{4}$ como parte de una mayor autonomía y flexibilidad que beneficia tanto al trabajador, a través de la llamada movilidad interna hacia funciones superiores o inferiores, como al empresario, que desplaza su empresa a otros territorios.

A su vez, la educación superior, adherida a las lógicas de un mercado laboral flexible, se convierte en uno de los lugares permanentes donde adquirir competencias e incentivar la movilidad de estudiantes hacia otros países para cursar estudios o hacer prácticas externas con el objeto de incrementar conocimiento y enriquecimiento personal. En este contexto, el impulso de la movilidad en trabajadores, desempleados, jóvenes, estudiantes y empresarios ingresa como parte de la racionalidad estatal, investida de una capacidad prácticamente mística para producir una población más emancipada y adaptable a un nuevo orden mundial.

El presente trabajo tiene como objetivo analizar una de las políticas migratorias que consagran la movilidad de jóvenes españoles hacia otros países, como parte de una forma natural y aceptable de estar en el mundo en un permanente estado de autoconstrucción personal. Para llevar a cabo este análisis apelamos a una perspectiva socioantropológica de

${ }^{2}$ Este artículo se realizó en el marco del proyecto de investigación titulado, "La nueva emigración desde España: perfiles, estrategias de movilidad y activismo político transnacional" y financiado por Ministerio de Economía y Competitividad. Plan Estatal de Investigación, Desarrollo e Innovación Orientada a los retos de la Sociedad. I+D+I CSO2016-80158-R (2015-2019).

${ }^{3} \mathrm{He}$ optado por escribir estado con minúscula como parte de un planteamiento analítico proveniente de la antropología, que intenta distanciarse del carácter cosificado del objeto expresado por ese término, el cual presupone una unidad homogénea y una relación de externalidad con las fuerzas sociales y económicas.

${ }^{4}$ Nos referimos a las reformas laborales llevadas a cabo en 2010 por el gobierno socialista (Partido Socialista Obrero Español) y la de 2012, realizada por gobierno conservador (Partido Popular). Estas políticas fueron forzadas por dichos gobiernos como parte de las llamadas políticas de austeridad impuestas por los organismos internacionales (Unión Europea, FMI) durante los últimos años causando altos niveles de precarización, pobreza y condiciones extremas de vulnerabilidad social. 
estudio de las políticas públicas (Franzé, 2013). Dicha perspectiva nos permite reflexionar sobre la llamada movilidad de los jóvenes, impulsada desde la denominada Secretaría de Estado de Migraciones, como parte de técnicas de gobierno encarnadas en un saber institucional y sustentadas en un discurso social que conjuga figuras históricas del pasado (conquistadores, aventureros), junto a valores de élites económicas globales actuales, del que se extraen un modelo para la acción y referentes de significado cultural (Corrigan y Sayer, 2007; Bourdieu, 2014; Shore y Wright, 1997; Ong, 2006).

Siguiendo a Bourdieu y Wacquant (2005), entendemos la Secretaría de Estado de Migraciones ${ }^{5}$ como parte de un campo burocrático compuesto de diferentes organismos jerárquicos, la Secretaría General de Inmigración y Emigración, la Dirección General de Migraciones y la Dirección General de Integración y Atención Humanitaria y otras dependencias de apoyo jurídico-administrativo. En este campo burocrático, agentes gubernamentales y no gubernamentales mantienen múltiples relaciones en torno a un nuevo objeto de intervención: la movilidad de los jóvenes de origen español a través de los límites territoriales. Como hemos mencionado, entendemos este tipo de intervención no en términos normativos, sino como dispositivos de saber-poder (Foucault, 2006) destinados a formar y naturalizar ciertas conductas en los jóvenes basadas en la construcción de sí mismos a través del aprendizaje permanente o el trabajo virtuoso (voluntario) que provee crecimiento personal o beneficio hacia otros significativos (marginales, excluidos, afectados por guerras, catástrofes). Esto puede rastrearse en el corpus que conforman leyes, programas, documentos, folletos o publicaciones en sitios electrónicos, reflejado en la Secretaría de Estado de Migraciones en cuanto a la denominada movilidad de jóvenes españoles. Un corpus que, en este trabajo, utilizamos no solo como fuentes secundarias de las que extraer datos objetivos y recuperar las características de determinada política pública, sino para llevar a cabo una lectura etnográfica del mismo, atenta a su conformación como fuente de conocimiento en el contexto estatal, político e histórico en el que se produce, y cuyos referentes no se centran exclusivamente en el marco de una única institución (Stoler, 1995; Gupta, 1995). En este sentido, las aportaciones de una historia cultural crítica sobre la materialidad de dicho corpus, formas, estructuras, dispositivos y convenciones que constriñen la producción de sentidos, cobran especial relevancia en este trabajo ya que nos permite prestar atención a los referentes culturales y las representaciones de las que los escritos se nutren, en base a contextos de producción, relaciones y formas de apropiación (Chartier, 2000).

\footnotetext{
${ }^{5}$ La Secretaría de Estado de Migraciones forma parte del Ministerio de Trabajo, Migraciones y Seguridad Social del actual gobierno socialista (Ministerio de Empleo y Seguridad Social durante el gobierno del Partido Popular, 2011-2018) y es la encargada de desarrollar y dirigir las políticas referidas a inmigración y emigración.
} 
La mayoría de las políticas de intervención en torno a la inmigración y emigración impulsadas por la Secretaría de Estado de Migraciones durante la última década, han sido analizadas desde la sociología como parte de dispositivos de integración para inmigrantes dentro de la comunidad nacional (Fernández, 2018). También se han examinado los programas de retorno de inmigrantes a sus países de orígenes (Perella y Petroff, 2014) y los mecanismos de asistencia en el extranjero (subvenciones) a personas mayores de origen español que deciden retornar al país (López de Lera, 2010). Menos interés académico han despertado las lógicas culturales y sociopolíticas de los programas de movilidad de jóvenes españoles que se han implementado partir de 2010 en la mencionada institución burocrática, $\mathrm{y}$ en los que adquieren un papel apreciable los repertorios técnicos y morales de profesionales del ámbito económico y empresarial. Estos agentes no gubernamentales, legitimados por el estado para hablar y actuar sobre la llamada movilidad internacional, resultan relevantes para este análisis. Los mismos operan como principales impulsores de un conjunto de proyectos en la red, exhibidos en las páginas web de la Secretaría de Estado de Migraciones, destinados a liberar o atraer las llamadas energías creativas de los jóvenes interesados en circular de manera segura por diferentes espacios laborales y geográficos bajo principios sobre el que se estructura gran parte del actual sistema social, político y económico (Boltanski y Chiapello, 2002).

Comenzamos este artículo con un primer apartado, que nos permitirá situar la aparición de los programas de movilidad de jóvenes en el marco de las actuales condiciones capitalistas. Destacamos en este apartado el poder clasificador de las fronteras geopolíticas y culturales europeas que ordena jerárquicamente a los grupos, produciendo y recreando simbólicamente marcadas distinciones (raza, género, nacionalidad, clase, edad). Partimos del supuesto de que estas fronteras funcionan como filtros diferenciales (Kearney, 1996; Heyman, 2011; Stephen, 2018) de sectores de población, tanto para segregarlos como para integrarlos dentro de un territorio nacional a fin de cumplir determinadas metas económicas y políticas (Turner, 2003).

En un segundo apartado, nos centramos en los saberes y lógicas culturales que sustentan estas políticas migratorias, producto de una trama de relaciones entre agentes gubernamentales y no gubernamentales (funcionarios, expertos, élites económicas, empresarios), a partir de la cual se reproducen determinadas lógicas de desigualdad y diferenciación. En el último apartado, analizamos cómo frente a estos nuevos saberes e intervención estatal, emerge una serie de tensiones y disputas interpretativas dentro del campo de poder político nacional y transnacional (partidos políticos, organizaciones de españoles en el extranjero, etcétera), que cuestionará el marco discursivo hegemónico sobre las movilidades internacionales desde el cual redefinir nuevas subjetividades sociales y políticas. 


\section{ENSAMBLAJES DISCURSIVOS SOBRE LA MOVILIDAD EN EL NUEVO ORDEN MUNDIAL}

En el marco de los procesos contemporáneos de transformación de las relaciones sociales de producción, en los que convergen determinadas formas de organización política y económica, autores como Smith (2010) o Harvey (2007) plantean que los estados neoliberales se apoyan en proyectos hegemónicos donde no se busca prevenir de forma extensiva que los excedentes de población se conviertan en disfuncionales para el orden social. Siguiendo a Smith (2010), se pretende establecer bajo determinadas relaciones de poder, un proceso selectivo en la medida en que esta población pueda seguir contribuyendo a un proyecto productivo formal o informal, en un determinado espacio económico o trasladándose con el objeto de constituir nuevos mercados de trabajo o abastecerlo donde sea necesario de acuerdo a su propia dinámica o expansión.

Teniendo en cuenta que las actuales dinámicas de acumulación capitalista no solo crean espacios de desnacionalización aptos para el desarrollo del mercado de capital global y financiero, sino también nuevas formas de producción, circulación y utilización de la fuerza de trabajo (Sassen, 2004; Ong, 2006; Harvey, 2007), nos interesa recuperar el carácter ambiguo y contradictorio que mantienen los estados nacionales en la selección de grupos dotados de valor específico para circular de forma constante por diferentes espacios geográficos, laborales y sociales. En este sentido, nos resulta relevante la mediación de los actuales estados nacionales europeos que buscan mejorar su posición competitiva en el mercado global (Harvey, 2007), favoreciendo la redistribución de sectores de población hacia determinados ámbitos productivos a través de mecanismos político-legales, atendiendo a principios de distinción y jerarquización que son propios de los procesos de organización de la mano de obra para un mercado de trabajo global. Entendemos la mediación de los estados nacionales a través del poder de sus fronteras geográficas y culturales (Kearney, 1996) no como un simple elemento intermediario, sino como un factor fundamental que ayuda, a través de sus sistemas burocráticos, espacios de intervención, control fronterizo, disposiciones y saberes, a configurar y dotar de valor (en sentido material y simbólico) a determinados sectores de población en el marco de las actuales relaciones sociales de producción.

En los últimos años, los estados europeos suelen adherirse a una serie de matrices discursivas comunes en torno a la organización y redistribución de la población extranjera que no se encuentra libre de jerarquizaciones. Se suele hacer de la población ajena a la comunidad política-nacional una fuente de prestigio por sus componentes productivos, habilidades y tolerancia al riesgo, favoreciendo su movilidad internacional (empresarios, inversores, trabajadores cualificados) o de discriminación (refugiados, desplazados, ilegales, etcétera), inspirando lo que Fassin (2016) denomina políticas de la compasión y/o represión. 
Los dispositivos destinados a favorecer la denominada movilidad internacional de extranjeros considerados cualificados y útiles, reflejados en comisiones, reuniones e informes provenientes de los organismos internacionales (OCDE, Unión Europea), inducen a convertir en asunto prioritario para los estados nacionales no sólo la entrada de emprendedores e inversores, sino también la salida de ciudadanos (nacionales) en búsqueda de formación o empleo con el objeto de fomentar sus capacidades y el denominado espíritu emprendedor, y así contribuir a la economía europea (Comisión Europea, 2013).

El tropo de la flexibilidad se convierte en la pieza fundamental de las actuales políticas migratorias del gobierno español, dispuestas a potenciar, por una parte, la ágil y rápida llegada de emprendedores, inversores financieros y trabajadores designados como talentosos provenientes de otros países (Secretaría de Estado de Migraciones, 2015) y, simultáneamente, la salida de la población española. Especialmente, la de los denominados "jóvenes emigrantes cualificados" (Santos, 2013; Alaminos y Santacreu, 2010; Alcalde, Petroff, Cavalti y Alarcón, 2014; Ermólieva y Kudeyárova, 2014) que se encuentran desempleados y, según los agentes institucionales, que no poseen las garantías necesarias para desarrollar sus capacidades creativas o de autoinvención. Este aspecto se ve reflejado en el informe realizado por la representación española de la Organización Internacional de las Migraciones, titulado La emigración de Profesionales Cualificados: una reflexión sobre las oportunidades para el desarrollo (OIM, 2012). Encausar la migración para beneficios de todos, el cual tiene como principal destinatario a los funcionarios del gobierno español.

El objetivo de dicho informe es ejemplificar con evidencias numéricas de otros países europeos las acciones consideradas correctas en torno a la emigración actual de profesionales, e impulsar a los gobernantes a desarrollar un "cambio de mentalidad" para dejar de considerar la salida de españoles cualificados al extranjero como un "movimiento por necesidad", para entenderlo como un "movimiento de oportunidad" en un "mundo globalizado e integrado":

El objetivo de la acción pública debe ser el fortalecimiento de las condiciones nacionales y del tejido productivo de modo que la migración no sea una necesidad ante la ausencia de una demanda de calidad de estos profesionales en el propio país (entendido por demanda de calidad una demanda en condiciones internacionalmente competitivas), sino todo lo más, una decisión de oportunidad y de ventaja profesional en un mundo globalizado e integrado donde la mano de obra, como los otros factores de producción es móvil internacionalmente y no un atributo de un país (OIM, 2012, p. 4).

Este informe es un ejemplo que permite vincular aspectos financieros y económicos con la presencia de una ética de la responsabilidad que penetra en los indicadores de un nuevo orden mundial basado en las auditorias (Shore y Wright, 2015). De esta forma, se reafirma a través de datos el principal valor diferencial de estos jóvenes: el poder moverse como mano 
de obra para lograr una verdadera autorealización, aunque para ello deban dejar de ser parte de una comunidad nacional de la que sentirse miembro de pleno derecho.

Al mismo tiempo que las normativas internacionales apelan a la responsabilidad de los gobernantes para liberar parte de la población, especialmente los llamados jóvenes cualificados, se alienta al gobierno central a que, "si no logra el nivel de desarrollo idóneo necesario para poder ofrecer un retorno de calidad" de los "mejores desplazados", ponga en marcha a través de miembros consulares e "interlocutores representativos", definidos por "su éxito" profesional o el de "business angels" (mecenas económicos), "proyectos de desarrollo" en el país basados en la iniciativa del capital privado (OIM, 2012, p. 5).

Teniendo en cuenta la aplicación de las políticas económicas en el contexto español y las expresiones ideológicas y culturales que las acompañan, las justificaciones utilizadas por los agentes globales para la creación de estos nuevos dispositivos de gestión en torno a la movilidad de los mejores ${ }^{6}$ servirán de punto de apoyo preceptivo a funcionarios españoles para racionalizar y explicar las causas del conjunto de población que se ha marchado del territorio nacional en la última década (Ferrer, 2013; Alba y Fernández, 2015; Domingo y Blanes, 2015; Ródenas y Martí 2016; Romero-Valiente 2016; Ortega-Rivera et al., 2016; Pérez-Caramés et al., 2018). En el marco de la presentación pública del mencionado informe en España, el 30 de noviembre de 2012 la Secretaria General Inmigración y Emigración, Marina del Corral Téllez, realizó unas declaraciones sobre la salida de trabajadores cualificados reflejadas en diversos medios de comunicación, y que no se vieron exentas de polémicas:

Es cierto que la situación interna se suma a dicha capacidad de mirar al exterior, pero considero desvirtuados los discursos que sostienen que la salida de trabajadores cualificados españoles está estricta y únicamente vinculada a la situación de crisis (El País, 2012, s/n).

La celebración en torno a aquellos trabajadores españoles que han dejado de ser locales para abrirse al mercado internacional como un ámbito de oportunidades, se reproduce en eventos institucionales y apela, fundamentalmente, a diferentes referentes culturales del resbaladizo campo de expresión del carácter nacional español, tales como el llamado espíritu aventurero y conquistador. Cabe mencionar que a finales de siglo XIX el "espíritu aventurero" era atribuido a los emigrantes como parte de un profundo arraigo del carácter nacional, semejante al de los llamados conquistadores españoles. El mismo retrataba los valores, sentimientos y aspiraciones de las élites conservadoras y liberales, que a través de

\footnotetext{
${ }^{6}$ La movilidad de los mejores hace referencia al uso que algunos funcionarios, técnicos y políticos realizan para describir e intervenir sobre ciertos movimientos de población, no como categoría jurídico-administrativa, sino en tanto categoría que se nutre de referentes de significación moldeados por valores hegemónicos, en los se suelen destacar cualidades altamente valoradas por el orden capitalista actual: talento, competitividad, capacidad de hacerse a sí mismo.
} 
ellos obtenía la base moral para explicar la salida de miles de emigrantes que huían de la pobreza y la miseria, al mismo tiempo que ayudaba a fortalecer un "yo colectivo nacional" (Betrisey, 2017).

De esta forma, diversos agentes del gobierno fueron asimilando estas figuras que se expresaron hace más de un siglo para generar una línea de continuidad con una tradición de emigrantes con espíritu aventurero, reconocida en la actualidad a través del espíritu emprendedor que encarnan los jóvenes que se movilizan como consecuencia de una supuesta creatividad y adaptabilidad en múltiples ámbitos de creación artística, científico, empresarial, de trabajador asalariado, etcétera. ${ }^{7}$

En la revista oficial Carta de España, surgida durante el gobierno franquista (Estévez, 2010) y reeditada por la Secretaría de Estado de Migraciones; ${ }^{8}$ dentro de la sección denominada Españoles por el mundo se incluyen múltiples testimonios de jóvenes que se ajustan a los referentes culturales de aventureros y emprendedores con los que trabajan los actuales agentes institucionales para explicar la emigración actual. Estos testimonios son reconstruidos en dicho medio gráfico por medio de entrevistas, o lo que se denomina historias de casos, en las que suele destacarse la salida del país como parte de una búsqueda de puestos de trabajo que encajen con la experiencia laboral o de una formación previa en grandes ciudades europeas o norteamericanas. En el marco de estas historias de españoles por el mundo, las ciudades son presentadas como amables, multiculturales, repletas de oportunidades de aprendizaje y crecimiento personal para el conjunto de los trabajadores españoles, siempre que puedan vencer sus "miedos internos" (por ejemplo, no hablar el idioma) (Carta de España, 2016). Las grandes capitales (Londres, Nueva York, Sídney, entre otras) son la expresión de libertad donde emprender una nueva vida confiando en su propia suerte, tenacidad, buenas conexiones y trabajo intenso, siempre que estén dispuestos a conquistar, al igual que los antiguos conquistadores de las Américas, tierras lejanas a través de las tradiciones españolas (cocina, arte) (Carta de España, 2015) o globalizar la empresa conformando redes de relaciones adecuadas en el mercado mundial (Carta de España, 2014).

\footnotetext{
${ }^{7}$ Esto se puso en evidencia en múltiples actos institucionales que desarrollaron funcionarios de la Secretaría de Estado de Migraciones entre los años 2014-2016, como parte de sus rutinas burocráticas con asociaciones empresariales, cámaras de comercio y centros privados de enseñanza superior en el contexto nacional. También enconsulados o embajadas de algunas ciudades europeas de Reino Unido o Alemania donde la población española es numerosa.

${ }^{8}$ La revista Carta de España recogía en sus inicios noticias sobre el trabajo de emigrantes en sus nuevos lugares de orígenes, como parte de diversas y diferenciadas comunidades (gallega, andaluza, vasca, etcétera) en el extranjero. Desde la reedición de la revista en 2006, las secciones sobre emigrantes y trabajo se ven plagadas de referentes simbólicos del individualismo liberal inmersos en una única esencia colectiva fundada en la homogeneidad cultural que confiere la ciudadanía española.
} 


\section{PROGRAMAS DE MOVILIDAD INTERNACIONAL DE JÓVENES Y PROYECTOS EN RED: NUEVOS SABERES Y LÓGICAS CULTURALES ESTATALES}

En el año 2010 aparecieron publicados los primeros programas de movilidad internacional en el marco de la Secretaría de Estado de Migraciones para jóvenes de nacionalidad española, en los que se ponía en juego muchos de los referentes sociales y culturales señalados anteriormente. Estos programas fueron firmados principalmente con países que no pertenecen a la Unión Europea ${ }^{9}$ como Australia, Nueva Zelanda, Canadá y Japón, bajo el nombre "Work and Holiday", para que dichos jóvenes "puedan ampliar su experiencia vital, practicar idiomas en el extranjero y adquirir experiencia laboral " (Boletín Oficial del Estado, 2014, p. 73352) a través de la movilidad. La mayoría de estos programas se justifican con el siguiente encabezado:

Deseosos de favorecer la movilidad de los jóvenes, así como la cooperación y colaboración entre ambos países, y de reforzar la excelencia de los centros de enseñanza y la competitividad de las empresas, en particular pequeñas y medianas empresas, de ambos países.

Deseosos de desarrollar la posibilidad para los jóvenes ciudadanos de ambos países de adquirir una experiencia profesional relacionada con su ámbito de competencia; de añadir un complemento a su formación postsecundaria en forma de prácticas; o de perfeccionar sus conocimientos de las lenguas, la cultura y la sociedad del otro país, promoviendo así la comprensión mutua entre ambos países (Boletín Oficial del Estado, 2014, p. 73352).

Estos programas contemplaron la estancia en los lugares de destino por el plazo de un año, ya que este es el tiempo que duraba el visado emitido a través del cual los jóvenes podían realizar trabajos retribuidos o no, considerando de esta forma la posibilidad de establecer relaciones laborales no asalariadas. En lo referido a la movilidad por estudio, se consideró que los jóvenes pudiesen matricularse en cursos educativos o de formación que no excedan los cuatro meses, siempre que posean recursos propios para sufragar el coste correspondiente. La permanencia más allá de los plazos estipulados implicó según lo recogido en alguno de los programas la denominada readmisión con la ayuda consular, conocida también con el nombre de repatriación.

\footnotetext{
${ }^{9}$ Cabe mencionar que los programas analizados en este trabajo no agotan todos los programas que desde organismos nacionales e internacionales, a partir de la década de los ochenta, han tomado como objeto de intervención la movilidad de jóvenes españoles por el contexto europeo. Entre ellos, cabe mencionar el Programa Erasmus y Programa Erasmus Plus destinado a la movilidad estudiantil dentro de la llamada internalización de la Educación Superior financiado por la Comisión Europea.
} 
Ahora bien, no todos los denominados jóvenes, entre 18 y 35 años, tendrían las mismas posibilidades de participar en estos programas de auto-realización personal mediante la movilidad. En primer lugar, deberían acreditar una formación universitaria de al menos dos años, no tener familia a cargo, poder autofinanciarse, pagarse el seguro médico y billete de avión (ida y vuelta), tener ahorros, no tener antecedentes penales y poseer un nivel de idioma mínimo del país de destino, puesto que se considera que la estancia en ese país mejorará el nivel de idiomas. En un contexto donde las condiciones de vida en destino importan menos que la posibilidad misma de partir, este joven tipo debería responder a una trayectoria social marcada por recursos económicos, sociales y educativos ampliamente diversificados que le permitiría planificar la partida en los términos establecidos por los acuerdos entre los gobiernos.

En términos generales, estos convenios constituyeron un espacio altamente regularizado y condicionado por una intervención y participación de los estados firmantes, presentados de forma técnica y neutral, apelando, generalmente, al discurso global de los organismos internacionales (Organización Internacional para las Migraciones, Banco Mundial, Comisión Europea) también interesados en la formación profesional. A modo de ejemplo, el programa de Formación Profesional Dual en Alemania, firmado con España y publicitado por la mencionada Secretaría de Estado de Migraciones, estuvo destinado a captar jóvenes españoles para realizar prácticas laborales. El gobierno alemán dejó constancia de que no se encargaría de buscar empleo o el lugar donde realizar tales prácticas, sino que se presentó como facilitador y orientador a la hora de tramitar la residencia en el lugar.

Esta representación de estado facilitador es compartida por los funcionarios y representantes del gobierno español encargados de intervenir en los programas de movilidad como parte de las políticas migratorias. En este marco, adquieren relevancia lo que denominamos proyectos en red que impulsan la movilidad de jóvenes en base a saberes profesionales provenientes de la gestión empresarial. Estos proyectos estaban encaminados hacia un objetivo muy preciso: lograr que los denominados jóvenes entusiastas con ciertos atributos personales (abierto al mundo, sin carga familiares, etcétera) puedan lograr el ansiado crecimiento personal e inserción laboral en el exterior. ${ }^{10}$

El sentido prescriptivo de los principales saberes relacionados con la gestión de la movilidad de trabajadores o expatriados en el contexto español (Espinosa y Verdeal, 2007; Álvarez y Gómez, 2012), ${ }^{11}$ destinados comúnmente a los directivos empresariales que

${ }^{10}$ Los programas de movilidad para jóvenes firmado con otros países que hemos analizado no contemplan subvención financiera. Por el contrario, los proyectos en red desarrollados por empresas privadas han obtenido entre 2011 y 2018 una financiación pública que oscila entre 10000 euros a 1000000 de euros.

${ }^{11}$ La literatura sobre gestión empresarial que surge en los años noventa en el marco de la internalización de las empresas españolas se centra en lograr una buena organización de la 
necesitan desplazar personal calificado a filiales extranjeras, se hace extensivo en los mencionados proyectos en red para jóvenes españoles. De esta forma, se destaca la movilidad como una oportunidad para realizarse personalmente, conocer otras culturas y vivir en un espacio de libertad. Todo ello siempre que hayan acumulado recursos económicos y educativos objetivados en títulos (idiomas, licenciaturas, máster, doctorados) y presenten lo que estos manuales de gestión empresarial denominan habilidades de líder global y una conciencia internacional. Siguiendo a Ong (2006), desde los años ochenta una parte importante de la socialización en estos valores y principios se establece en los ámbitos universitarios norteamericanos y europeos orientados por doctrinas neoliberales, que ofrecen entrenamientos adecuados para conseguir la ansiada movilidad, correr riesgos, y así fortalecer un ethos global mediante el desarrollo de cursos específicos en múltiples ramas del saber (ciencias experimentales, ciencias sociales, humanidades, etcétera) o prácticas externas, mayoritariamente no remuneradas, en múltiples empresas.

Uno de los primeros proyectos difundido en la página web de la Secretaría de Estado de Migraciones fue la página web CEXT, Ciudadanía en el Exterior, llamado el portal de jóvenes en el extranjero. En el año 2014 se podía leer en dicho portal lo siguiente:

Tanto si eres de los que acabas de dar el salto y acabas de llegar a tu nuevo país de residencia como si llevas ya un tiempo en el extranjero y te estás planteando la posibilidad del retorno, la nueva web de CEXT es para ti. Porque nos hemos adaptado a las necesidades de una generación valiente. Una generación de jóvenes españoles que han sabido superar el miedo a lo desconocido y han entretejido en su biografía un paisaje de aeropuertos, despedidas y nuevos encuentros. Una generación que sabe que una vez superadas las fronteras más difíciles, que son las mentales, los imposibles desparecen. Pero como al vivir fuera siempre surgen dudas y al hándicap del idioma o la cultura le suelen acompañar dudas acerca de trámites burocráticos o simplemente ganas de compartir intereses y aventuras con gente en nuestra misma situación, te ofrecemos la posibilidad de registrarte, de forma muy fácil, en nuestra web (Ciudadanía exterior, 2014, s/n).

$\mathrm{Al}$ igual que en este caso, la mayoría de los mencionados proyectos en red trabajan para potenciar las capacidades personales del que se mueve en un supuesto mundo sin obstáculos, asumiendo el rol de contrapeso psicológico que sirva para romper el posible aislamiento y conectarlos con otras personas con el fin de forjar vínculos que se presentan como

movilidad de los llamados trabajadores de alta calificación que posean, grandes aptitudes personales y mentalidad abierta, mediante recomendaciones prodigiosas plasmadas en múltiples informes destinados a crear un sentido de cultura organizacional global y trabajar en redes flexibles. 
permanentes, disponibles cada vez que se necesiten, y fundamentales para su crecimiento económico. Estos programas parten del supuesto de que la movilidad puede provocar un conjunto complejo de sentimientos, miedos y ansiedades que paralicen a los jóvenes en su lugar de origen. De esta forma, dichos programas se preparan para prescribir soluciones mediante la figura del coach, o tutor virtual, que pondrá su empeño, mediante el asesoramiento y la motivación, para encauzar a los jóvenes en un conocimiento personal, descubrir sus capacidades internas, y prescribir soluciones ante las ansiedades que pudiese suscitar vivir en un mundo que se considera en permanente movimiento y lleno de oportunidades para los jóvenes emprendedores que saben aprovecharlas.

Siguiendo estos postulados, en los últimos años el estado ha financiado proyectos en red para jóvenes en el exterior (menores de 35 años) que posean lo que consideran una idea emprendedora e innovadora con el objeto de ser premiada y consultada a expertos internacionales. También abundan proyectos que funcionan a través de sistemas de alertas sobre becas, cursos de emprendedores para jóvenes que buscan oportunidades en Europa, o para mejorar la inserción laboral de los españoles que residen en el extranjero en determinados sectores productivos (nuevas tecnologías, comunicación audiovisual, marketing, gestión empresarial negocios, turismos, etcétera). ${ }^{12}$

Por otra parte, los proyectos en red que provienen de organizaciones empresariales, como el impulsado por la Cámara de Comercio de España en Bélgica y Luxemburgo, propusieron conformar un Programa Erasmus para jóvenes emprendedores, financiado por la Unión Europea que tengan una duración de entre uno o seis meses con el objetivo de crear redes y establecer contactos entre jóvenes españoles que se consideren "seriamente futuros empresarios" y puedan demostrar, sin especificar claramente cómo, su motivación y compromiso con empresarios experimentados de otros países. La participación en estos proyectos por parte del futuro joven empresario estará condicionada a "contribuir al desarrollo del negocio del empresario que lo acoja" y "estar dispuesto a sufragar los gastos de su estancia en el extranjero que superen la subvención de la UE" para conseguir "nuevas ideas emprendedoras" (Cámara Oficial de Comercio de España en Bélgica y Luxemburgo, 2014, s/n). Estos programas se sustentan en la existencia de una jerarquía de conocimiento (los que poseen conocimiento emprendedor frente a los desposeídos del mismo), donde los promotores mencionados (Íbidem) operan como agentes moralizadores y reguladores de unas relaciones laborales que, más allá de sus formas y características, serán ambiguamente traducidas como parte de una gratificación para los jóvenes que se están formando en el devenir emprendedor. Esta propuesta es concebida como parte de un esfuerzo común entre

${ }^{12}$ Durante el año 2016 y 2017 algunas fundaciones o centros universitarios privados, como por ejemplo la Fundación Universitaria de las Palmas, o la Facultad de Turismo de Oviedo, comenzaron a formar parte de los proyectos financiados por la Secretaría de Estado de Migraciones, ofreciendo asesoramiento en orientación laboral y talleres de emprendimientos. 
todos los agentes implicados en la que se soslayan los mecanismos que regulan la transferencia de valor de los jóvenes como mano de obra disponible en el marco de las actuales estrategias empresariales (disminución de salarios y la precarización laboral). ${ }^{13}$

Si bien muchos de los proyectos en red están destinados a preparar la salida de jóvenes y su posible inserción en otros mercados europeos, el gobierno también financia proyectos de retorno al país, siempre que se pueda comprobar haber adquirido en el extranjero ideas innovadoras. Entre ellos, podemos mencionar uno de los primeros proyectos denominado Ideas de Ida y Vuelta, cuyo objetivo se centra en asesorar a aquellos jóvenes (no mayores de 34 años) que han adquirido ideas innovadoras durante su estancia en el exterior con el objeto de poder impulsarlas de regreso a España. Así en el año 2014 los creadores de este programa presentan en la página web una propuesta cargada de referentes y símbolos de la cultura popular española:

El Programa "Ideas de Ida y Vuelta" hace un símil con los cantes flamencos. Se emplea la expresión «de ida y vuelta» por la antigua creencia de que estos estilos habían llegado a América a través de los emigrantes españoles, se habían transformado allí y, con el regreso de los emigrantes y con la vuelta a los orígenes de sus descendientes, enriquecieron nuestro patrimonio folclórico, cultural y musical. Entre estos cantes «de ida y vuelta» tenemos la Guajira, la Rumba, la Milonga o la Colombiana... La idea es muy sencilla. Tú estás residiendo actualmente en el extranjero, has acumulado un conjunto de experiencias personales y profesionales, y tienes una idea que piensas que puede representar una oportunidad de negocio en España...Pues bien, a través del Programa "Ideas de Ida y Vuelta" vamos ayudarte a analizar la viabilidad de esta idea, vamos a capacitarte para su puesta en marcha en España... (Emprendedores, 2014, s/n).

En la actualidad, los proyectos pensados para el retorno hacen hincapié en canalizar el lado innovador y liberador de la experiencia individual en el exterior, destacando la necesidad de ponerla al servicio del bien común del país. Para ello potencian un tipo de emprendimiento que ha sido capaz de incorporar aspectos del llamado desarrollo sostenible, sin dejar de lado la retórica de la empleabilidad y principios ecológicos de algunas empresas (Retorna en Verde-Asemfo; Eco-Emprendimiento, Iudicem-Perú, entre otras). Estos principios ecológicos se inscriben en lo que Boltanski y Chiapello (2002) han denominado "marketing ecológico", que incorpora demandas del cuidado del medioambiente y la autenticidad para obtener nuevos mercados de consumos.

Los marcos de significación cultural que sustentan en gran parte el conjunto de los programas y proyectos analizados asumen la existencia de unas cualidades naturales en ciertos jóvenes españoles que los predisponen a aprovechar las oportunidades que provee "el

${ }^{13}$ Si bien en sus comienzos este proyecto despertó el interés y el apoyo de la Secretaría de Estado de Migraciones, en la actualidad se encuentra financiado por la Unión Europea. 
mundo en red" (Boltanski y Chiapello, 2002) con el objeto de prosperar, frente a otros menos aventajados que suelen eludirlas y sobre los que se descarga la responsabilidad de su propia situación precaria. Estos presupuestos socioculturales, entendidos como el resultado de una determinada formación histórica y de poder, se convierten en dominantes en el contexto analizado y son sustentados por ideologías liberales e individualistas que involucran a los agentes sociales en una praxis constante de autoconstrucción. En medio de este devenir permanente, el no moverse o no cambiar de los sujetos, como ya advirtiera Sennet (2006) a través de múltiples estudios de casos de los afectados por las actuales condiciones del capitalismo tardío, se convierte en sinónimo de fracaso (quedarse fuera de juego), o causa de crítica por no estar dispuestos a asumir los sacrificios exigidos por los desplazamientos sociales o geográficos que llevar a convertirse en alguien adaptable y flexible (Boltanski y Chiapello, 2002).

Estas nuevas formaciones culturales que expresan, modelan y constituyen subjetividades nos permitiría comprender mejor el punto de vista de muchos jóvenes españoles, que a través de estos programas estatales o por su cuenta se han trasladado a vivir al extranjero en los últimos años. Ahora bien, entendemos que esto no se produce como meros replicantes de una estructura o cultura dominante, sino producto de experiencias y subjetividades complejas formadas dentro de un marco de relaciones de poder ampliamente desiguales que saturan sus vidas cotidianas. ${ }^{14}$

\section{TENSIONES INTERPRETATIVAS EN EL CAMPO POLÍTICO: "FUGAS DE CEREBROS" Y "EXILIO"}

El relato dominante de la movilidad internacional en las rutinas burocráticas, sustentado por el conjunto de repertorios técnicos y morales que hemos analizado, no se ha visto exento de tensiones y conflictos, dando lugar a múltiples formas de confrontación e impugnación por parte de grupos situados dentro del campo político nacional (partidos políticos, asociaciones, movimientos de protesta, entre otras) y transnacional (grupos y asociaciones de españoles en el extranjero). Las principales confrontaciones públicas se expresaron en el ámbito parlamentario, el cual entendemos siguiendo a Bourdieu (2014, p. 484) como un lugar de consenso regulado o de disenso dentro de ciertos límites entre grupos que compiten por el poder político. Estas confrontaciones se iniciaron por parte de sectores políticos progresistas al impugnar aquellas representaciones que consideran la salida de jóvenes hacia el extranjero

\footnotetext{
${ }^{14}$ Estos planteamientos abren un camino analítico que no podemos cerrar satisfactoriamente en este trabajo ni atender a todas sus dimensiones y requiere un análisis de mayor profundidad que hemos comenzado a construir a partir de un trabajo de campo realizado entre 2016 y 2018 con emigrantes españoles en dos ciudades de Reino Unido (Edimburgo y Londres).
} 
como parte de una oportunidad, para considerarla como pérdidas para el país, reflejada en la categoría de fuga de cerebro.

El 17 de abril de 2013, tal y como quedó registrado en el Diario de Sesiones del Congreso de Diputados la diputada, María González Veracruz del Partido Socialista, interpela a la Ministra de Empleo y Seguridad Social en el Congreso de los Diputados, con la siguiente pregunta: “¿qué medidas ha tomado el gobierno ante la situación de los jóvenes que se tienen que ir de España a buscar empleo, una tragedia que cada día es mayor sin duda?" (Diario de Sesiones del Congreso de Diputados. Pleno y Diputación permanente, 2013, p. 17). En este sentido, la respuesta de la Ministra se centra en la creación de la ley 14/2013 destinada al "emprendimiento como salida a esta situación”, poniendo en juego en su argumentación los valores del individualismo liberal para dar cuenta de comentada salida de los jóvenes como un proceso en el que "todos ganan":

- Señora diputada, es verdad que muchos jóvenes y no tan jóvenes han salido de España en busca de oportunidades por la crisis. Eso se llama movilidad exterior (Rumores), porque hay gente que busca oportunidades laborales y formativas. Pero es una realidad, señora diputada, que desgraciadamente no empezó ayer, 50.000 jóvenes salieron con los Gobiernos socialistas fuera de nuestro país. Esa idea de movilidad también lleva una idea de intercambio en 2012, 17.300 españoles residentes en Europa por la crisis_-, y vienen también a España. Hay 30.000 alemanes, 40.000 del Reino Unido y 63.000 italianos en nuestro país. Lo que queremos es trabajar para que el que quiera salir, salga, pero para que el talento huido que haya salido por la crisis, vuelva cuanto antes. Esa es su obligación y también la de este Gobierno sin duda ninguna. [Aplausos] (Diario de Sesiones del Congreso de Diputados. Pleno y Diputación permanente, 2013, p. 17)

La utilización de un lenguaje técnico-economicista, que realizan los políticos de diversas tendencias ideológicas sobre la salida de jóvenes al extranjero, basado en sumas y restas, logra desplazar el discurso a un registro donde el desacuerdo social es poco probable: la existencia de una "ausencia ejemplar" (los mejores, los más formados, más preparados, etcétera) que se piensa como temporal de la "tierra de origen" (Sayad, 2010).

Cabe destacar que las disputas que se dieron en el parlamento entre grupos políticos fueron establecidas previamente en medios de comunicación y redes sociales por parte de movimientos organizativos de españoles que emigraron a ciudades de Reino Unido, Francia, Alemania o de países latinoamericanos (Argentina, Brasil, Ecuador, entre otros). En un comienzo, la organización de emigrantes en red denominada Marea Granate, iniciada en 2013, y alineada a algunos movimientos de protesta en el contexto español (otras Mareas -Blancas, Verde- ${ }^{15}$, Juventud sin Futuro), se caracterizó desde el exterior por ofrecer

15 Las llamadas Mareas fueron identificadas con diferentes colores relacionados con la actividad desplegada por los trabajadores que protestaban contra las medidas de austeridad 
justificaciones diversas a las dominantes a través de sus diferentes páginas web y de diferentes periódicos españoles. En términos generales, estos grupos intentaron invalidar la línea de continuidad con el discurso político que considera el impulso aventurero de sus emigrantes, aunque no necesariamente se rompe con el marco común discursivo basado en la ausencia de los mejores formados, sobre las que seguirán gravitando algunas de las críticas, demandas y estrategias colectivas.

El eje discursivo de este movimiento se sustenta en el carácter forzado que contiene el proyecto emigratorio actual de los considerados jóvenes mejores preparados del país, para desafiar la explicación oficial sobre la movilidad internacional. La categoría "exilio económico" se convierte en el soporte unificador de las protestas, y amplía dentro del campo de lucha hegemónica el sentido del exilio, asociado comúnmente en el contexto europeo y latinoamericano a las persecuciones, guerras, conflictos armados, para considerar no menos forzada la salida por la pérdida de los puestos de trabajo, los bajos salarios del país bajo el lema "no nos vamos, nos echan".

En términos generales, la crítica social y las prácticas de movilización llevadas a cabo por este movimiento combinan protestas, demandas y negociaciones con el estado español, a través de algunas de sus instituciones burocráticas, destinadas a obtener un acceso a derechos (mejoras en el derecho al voto por correo o no perder prestaciones de la sanidad pública), producto de una desconexión forzada de la considerada tierra de origen. Estos discursos reivindicativos serán entablados en términos de obligaciones y derechos morales contractuales con la comunidad nacional de pertenencia, nutridos por un sentimiento de indignación que pondrán en cuestionamiento el deber ser de naturaleza simbólica del estado que es representado como sistema benefactor e integrador. De esta forma, se recupera la imagen de un estado negligente que causa el desplazamiento de un amplio sector de sus ciudadanos, al mismo tiempo que se invoca el reconocimiento político en el extranjero como "víctimas necesarias" y no "disfuncionales" dentro de los términos de la actual hegemonía selectiva de los proyectos estatales neoliberales (Smith, 2010).

\section{CONCLUSIONES}

En este trabajo nos hemos centrado en los discursos y agencias burocráticas del estado central destinadas a gestionar la salida de población española como parte de las políticas migratorias, y su interconexión con organismos internacionales que trabajan para lograr una armonización legislativa mundial con respecto a la movilidad internacional de la población seleccionada con base en determinados atributos. Como sugieren Shore y Wright (1997),

ejecutadas por el estado español. Por ejemplo, las Mareas Blancas, hacían referencia a la organización de diversos colectivos de la sanidad pública que utilizaba sus batas blancas durante las protestas. El caso nombre Marea Granate responde al color del pasaporte que los españoles debían utilizar para salir del país. 
analizar estas políticas desde un punto de vista antropológico implica considerarlas no sólo un ejemplo de persuasión y legitimación, sino también una forma particular de acción social y simbólica que incide en la construcción de nuevas categorías del individuo y de subjetividad.

De esta forma, mezclando argumentos técnicos y morales que remiten a la movilidad como parte de una liberación, emancipación, o promesa de autorrealización, se espera que determinado sector de la población española pueda integrase a sociedad receptora que elija como destino, a través de los programas de movilidad y los proyectos en red, en el trascurso de una educación constante. También se espera una integración de estos sectores en otros mercados laborales que no se ven exentos de las actuales formas de producción capitalista, las cuales se suelen asumir como parte de la naturalidad del mundo social, ajena a conexiones y relaciones económicas, políticas e ideológicas históricamente determinadas.

En este contexto, se vuelven efectivas las distinciones que se generan desde los organismos gubernamentales y no gubernamentales en términos de jóvenes locales/móviles vinculadas a los mencionados mercados laborales. El uso de estas distinciones permite mantener los procesos de desigualdad vigentes, abandonando a los que no aprovechan las oportunidades de desplazarse por considerar que poseen ciertas cualidades naturales que los fijan a un lugar y, al mismo tiempo, facilitando la distribución de los aventajados en la medida que cumplan con una serie de requisitos altamente valorados por el capital global (recursos económicos, falta de cargas familiares, predisposición al riesgo) que sustentan la existencia del "nuevo espíritu del capitalismo" (Boltanski y Chiapello, 2002). La existencia de este nuevo espíritu del capitalismo generaliza las reglas de una cultura empresarial, entendida no como simples recetas económicas sino como modos de pensar, decir y hacer en un mundo global y reticular que desborda a un gobierno o institución y se hace extensivo a otros ámbitos sociales: el trabajo, la escuela, la universidad, etc. que merecen trabajos etnográficos en profundidad.

En este sentido, la eficacia con que suele operar el concepto de la movilidad internacional en los nuevos dispositivos y reglamentaciones del estado español en relación con sus políticas migratorias, no obedece exclusivamente a la traslación directa del punto de vista de una clase dominante o un sector empresarial global, sino que se instala en un horizonte de supuestos subjetivos que están previamente disponibles en la consciencia social. Esto posibilitará, al menos durante un tiempo, el fortalecimiento de nuevas representaciones y significados de aparente lógica y coherencia orientados a liberalizar parte de la población hacia otros espacios geográficos y laborales.

No obstante, al considerar el carácter abierto y disputable alrededor de las creencias y representaciones sobre la movilidad internacional en el marco de campos de fuerza políticos contextualizados (parlamento, movimientos sociales), tenemos la posibilidad de alejarnos de interpretaciones que plantean la existencia de actores sociales que poseen una conciencia 
libre de ideologías dominantes o se encuentran sometidos al engaño. Todo ello mientras se extienden con fuerza las crudas consecuencias de la pobreza y la desigualdad entre sectores que, como bien plantea Smith (2010, p. 192), "se ven cada vez más excluidos de participar en una política de negociación [...] dentro de los términos de la actual hegemonía productivista que sólo permite negociar un reconocimiento selectivo", en términos de "los mejores" siempre y cuando continúen en el devenir de construirse a sí mismo.

\section{REFERENCIAS}

Alaminos, A. y Santacreu, O. (2010). La emigración cualificada española en Francia y Alemania. Papers. Revista de Sociología, 95(1), 201-211.

Alba, S. y Fernández, A. (2015). Nueva Emigración Exterior y Cuestión Laboral. Fundación $1^{o}$ de Mayo, (91), 3-19.

Alcalde, R., Petroff, A., Cavalti, L. y Alarcón, A. (2014). Las migraciones de españoles hacia los Estados Unidos en el siglo XXI: un análisis desde las migraciones cualificadas. Camino Real. Estudios de las Hispanidades Norteamericanas, 6(9), 13-38.

Álvarez, M. y Gómez, S. (2012). Políticas de expatriación en el contexto económico actual: visión de las empresas. Navarra: Ernst \& Young/IESE Business School/Universidad de Navarra.

Betrisey, D. (2017). El estado nación y la producción del conocimiento sobre emigración española a finales del siglo XIX. Revista de Diactelogía y Tradiciones Populares, LXXII, (2), 457-476.

Boletín Oficial del Estado. (2014). Aplicación provisional del Acuerdo entre el Gobierno del Reino de España y el Gobierno de Australia relativo al programa de movilidad para jóvenes. Ministerio de Asuntos Exteriores y Cooperación. Madrid: 3 de septiembre de 2014.

Boltanski, L. y Chiapello, È. (2002). El nuevo espíritu del capitalismo [Trad. M. Pérez, A. Riesco, R. Sánchez]. Madrid: Akal.

Bourdieu, P. (2014). Sobre el Estado. Cursos en el Collège de France (1989-1992) [Trad. P. González]. Barcelona: Anagrama.

Bourdieu, P. y Wacquant, L. (2005). Una invitación a la sociología reflexiva [Trad. H. Levesque]. Buenos Aires: Siglo XXI.

Cámara Oficial de Comercio de España en Bélgica y Luxemburgo. (2014). Programa Erasmus para jóvenes emprendedores [Entrada de blog]. Recuperado de https://ecamara.com/web/erasmus-jovenes-emprendedores/

Carta de España Online. (2014). "Spanish startups en la Tech City londinense" [Portal de la Ciudadanía $\quad$ Española]. $\quad$ Recuperado de http://www.inclusion.gob.es/cartaespana/es/noticias/Noticia_0323.htm 
Carta de España Online. (2015). "Pizarro, el conquistador de las tapas" [Portal de la Ciudadanía $\quad$ Española]. $\quad$ Recuperado de http://www.inclusion.gob.es/cartaespana/es/noticias/Noticia_0023.htm

Carta de España Online. (2016). "Irlanda para empezar una nueva vida" [Portal de la Ciudadanía $\quad$ Española]. $\quad$ Recuperado de http://www.inclusion.gob.es/cartaespana/es/noticias/Noticia_0358.htm

Chartier, R. (2000). El mundo como representación. Historia cultural: entre práctica y representación [Trad. C. Ferreira]. Barcelona: Editorial Gedisa.

Ciudadanía exterior. (20 de mayo 2014). El portal de los jóvenes españoles en el exterior [Entrada de blog]. Recuperado de https://www.cext.es/

Comisión Europea. (2013). Informe sobre la ciudadanía UE. Ciudadanos de la UE: vuestros derechos, vuestro futuro. Informe de la Comisión al Parlamento Europeo al Consejo al Comité Económico y Social Europeo y al Comité de las Regiones (2013). Bruselas: [Autor].

Corrigan, P. y Sayer, D. (2007). La formación del Estado inglés como revolución cultural. En M. Lagos y P. Calla (Eds.), Antropología del Estado: dominación y prácticas contestatarias en América Latina, (pp.41-116). Bolivia: INDH/PNUD.

Diario de Sesiones del Congreso de Diputados. Pleno y Diputación permanente. Cortes generales del Estado, Madrid: 17 de abril de 2013.

Domingo, A. y Blanes, A. (2015). Inmigración, migración y emigración en España: estado de la cuestión y perspectiva de futuro. Anuario de la Inmigración en España 2014. Barcelona: CIDOB.

El País. (30 de noviembre de 2012). "Un alto cargo de inmigración: los jóvenes emigran por "impulso aventurero". Autor, Recuperado de https://politica.elpais.com/politica/2012/11/30/actualidad/1354286966_753467.html

Emprendedores. (20 de mayo de 2014). Programa "Ideas de Ida y Vuelta" [Entrada de blog]. Recuperado de https://www.emprendedores.es/noticias-de-empresa/a45655/ideas-deida-y-vuelta/

Ermólieva, E. y Kudeyárova, N. (2014). La movilidad internacional de recursos humanos cualificados: Nuevas tendencias (el caso de España). Camino Real. Estudios de las Hispanidades Norteamericanas, 6(9), 39-55.

Espinosa, S. y Verdeal, J. (2017). Algunas reflexiones acerca de la movilidad internacional de los trabajadores. La internacionalización de la empresa española ICE, (839), 103-111.

Estévez, M. del P. (2010). Carta de España. La imagen oficial de la emigración española. Cuadernos de Historia del Derecho, (2), 103-128.

Fassin, D. (2016). La razón humanitaria. Una historia moral del tiempo presente [Trad. H. Pons]. Buenos Aires: Prometeo.

Fernández, B. (2018). La alteridad domesticada. La política de integración de los inmigrantes en España: actores y territorios. Barcelona: Edicions Bellaterra. 
Ferrer, A. (2013). La nueva emigración española. Lo que sabemos y lo que no. Zoom Político, (18), 2-20.

Foucault, M. (2006). Seguridad, territorio y población [Trad. H. Pons]. Buenos Aires: Fondo de Cultura Económica.

Franzé, A. (2013). Perspectivas antropológicas y etnográficas de las políticas públicas. Revista Antropología Social, (22), 9-23.

Gupta, A. (1995). Blurred boundaries: the discourse of corruption, the culture of politics and the imagined state. American Ethnologist: The Journal of the American Ethnological Society, 22(2), 375-402.

Harvey, D. (2007). Breve historia del neoliberalismo [Trad. A. Varela]. Madrid: Akal.

Heyman, J. (2011). Cuatro temas en el estudio de la frontera contemporánea. En N. Ribas Mateo (Ed.), El Río Bravo Mediterráneo. Las regiones fronterizas en la época de la globalización, (pp. 81-96). Barcelona: Edicions Bellaterra.

Kearney, M. (1996). Reconceptualizing the Peasantry: Anthropology in Global Perspective. Boulder: Westview Press.

López, D. (2010). Emigración, inmigración y retorno: tres etapas de un mismo fenómeno. Polígonos: Revista de Geografía, 20, 9-27.

Ong, A. (2006). Neoliberalism as exception. Chapel Hill: Duke University Press.

Organización Internacional para las Migraciones (OIM). (2012). La emigración de profesionales cualificados. Una reflexión sobre oportunidades de desarrollo. Encauzar la emigración para beneficios de todos. Elaborado por A. Díaz Gil. Octubre de 2012, Madrid: Ministerio de Empleo y Seguridad Social/Secretaría General de Inmigración y emigración.

Ortega-Rivera, E., Domingo, A. y Sabater, A. (2016). La emigración española en tiempos de crisis y austeridad. Scripta Nova. Revista Electrónica de Geografía y Ciencias Sociales, 20, 549-5.

Parella, S. y Petroff., A. (2014). Migración de retorno en España: Salidas de inmigrantes y programas de retorno en un contexto de crisis. Anuario CIDOB de la inmigración, 61-88.

Pérez-Caramés, A., Ortega, E., López, D. y Domínguez-Mujica, J. (2018). La emigración española en tiempos de crisis (2008-2017): análisis comparado de los flujos a América Latina y Europa. Notas de Población, (107), 11-40.

Ródenas, C. y Martí, M. (2016). La imagen estadística de la Emigración internacional en España: análisis de las nuevas fuentes en relación con la fiabilidad de las estadísticas de las variaciones residenciales. Boletín de la Asociación de geógrafos españoles, (72), 305326.

Romero-Valente, J. M. (2016). Los flujos migratorios en las estadísticas de origen y destino: la emigración de españoles a Europa (2008-2013). Cuadernos Geográficos, 55(2), 151172. 
Santos, A. (2013). Fuga de cerebros y crisis en España: los jóvenes en el punto de mira de los discursos empresariales. Áreas. Revista Internacional de Ciencias Sociales, (32),125137.

Sassen, S. (2004). Formación de las condiciones económicas para las migraciones internacionales. Ecuador Debate, (63), 47-62.

Sayad, A. (2010). La doble ausencia. De las ilusiones del emigrado a los padecimientos del inmigrado [Trad. Enrique Santamarina]. Barcelona: Anthropos.

Secretaría de Estado de Migraciones. (2015). Informe sobre la aplicación de la sección de movilidad internacional de la ley 14/2013, de 27 de septiembre, de apoyo a emprendedores y su internacionalización. Madrid: Ministerio de Empleo y Seguridad Social.

Sennet, R. (2006). La corrosión del carácter. Las consecuencias personales del trabajo en el nuevo capitalismo [Trad. D. Najmías]. Barcelona: Anagrama.

Shore, C. y Wright, S. (1997). Anthropology of Policy: Critical Perspectives on Governance and Power. Nueva York: Routledge.

Shore, C. y Wright, S. (2015). Governing by numbers: Audit culture, rankings and the new world order. Social Anthropology, 23(1), 22-28.

Smith, G. (2010). Hegemonía y superpoblación: Límites conceptuales en la antropología de los movimientos políticos. En V. Bretón (Rd.), Saturno devora a sus hijos, (pp. 175-194). Icaria: Desarrollo Rural.

Stephen, L. (2018). “Creating Preemptive Suspects National Security, Border Defense, and Immigration Policy, 1980-Present”. Latin American Perspective, 223(45), 7-25.

Stoler, A. L. (1995). Race and the education of desire: Foucault's history of sexuality and the colonial order of things. Durham, Carolina del Norte: Duke University Press.

Turner, T. (2003). Clase, cultura y capitalismo. Perspectivas históricas y antropológicas de la globalización. En J. L. García García y A. Barañano (Coords.), Culturas en contacto. Encuentros y desencuentros, (pp. 65-110). Madrid: Ministerio de Educación, Cultura y Deporte. 